\title{
Dietary Salt Intake, Blood Pressure, and Genes
}

\author{
Sara Lupoli • Erika Salvi • Cristina Barlassina
}

Published online: 1 June 2013

(C) Springer Science+Business Media New York 2013

\begin{abstract}
Our ancestors developed in environments characterized by salt scarcity; their salt intake was less than $1 \mathrm{~g} /$ day and efficient physiological mechanisms were evolved to retain salt. Nowadays, in many countries in the world, the current dietary salt intake is very high (10 g/day on average) and largely exceeds the recommended $5 \mathrm{~g}$ /day. Although not all studies agree, many evidences point to a relationship between high salt consumption, blood pressure, and its associated cardiovascular risk. Therefore, the adoption of a salt intake reduction is justified. Salt sensitivity, defined as blood pressure response to salt intake, is heterogeneous among subjects. Many authors have investigated the genetic bases of salt sensitivity, mainly with a candidate gene approach. Most of these findings need replication and much work is still necessary to identify the true genetic risk factors.
\end{abstract}

Keywords Salt $\cdot$ Sodium $\cdot$ Diet $\cdot$ Cardiovascular risk .

Salt-sensitivity · Prevention $\cdot$ Blood pressure ·

Hypertension · Genes · Single nucleotide polymorphisms

\section{Introduction}

Salt consumption has greatly changed over the millennia. Our ancestors, who lived 2 million years up to 10,000 years ago, were essentially hunters, they used to eat meat from wild animals, fruits and vegetables from uncultivated plants,

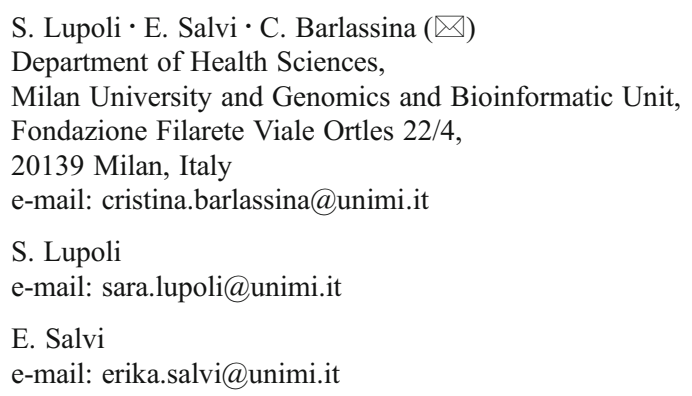

and salt was that contained in natural foods. Their usual diet contained $<1 \mathrm{~g}$ salt/day. Salt started to be used approximately 5,000 years ago when its property to preserve food was discovered. Later, the advent of cold techniques for food conservation caused a decline in salt use. Due to the recent increase in consumption of highly salted industrialized foods, salt intake is increasing again.

The terms "salt" and "sodium" are used in an interchangeable way. However, the two terms do not exactly mean the same thing. Dietary sodium is consumed as common salt: sodium chloride $(\mathrm{NaCl})$. Each molecule of salt is composed of an atom of sodium (Na) and an atom of chloride $(\mathrm{Cl})$. Chloride contributes more than sodium to the weight of the molecule and $1 \mathrm{~g}$ of salt means $0.4 \mathrm{~g}$ of sodium or $1 \mathrm{~g}$ of sodium equals $2.5 \mathrm{~g}$ of salt. However, in terms of health, what matters is sodium and the sodium content is what the food labels report.

The mean current salt intake in many countries is approximately $10 \mathrm{~g} /$ day and largely exceeds physiological needs and the recommended limit of salt $<5 \mathrm{~g}$ /day $(<2$ g of sodium) [1]. The sources of dietary salt vary between developed and developing countries. In Europe and North America, more than $75 \%$ of dietary salt comes from processed food, where it is added at manufacturing stage [2]: $10 \%$ is the natural sodium content and approximately $15 \%$ is added at home during cooking. This latter, rather than packaged food, is the major source of salt consumption in the developing countries [3, 4].

Salt, Blood Pressure, and Cardiovascular Risk

The first observation linking salt to blood pressure (BP) is reported in the Yellow Emperor's Classic of Internal Medicine, where it was stated: "the pulse hardens when too much salt is added" [5]. Then, many evidences originated from epidemiological studies [6,7] and randomized, clinical trials on dietary salt intake $[8,9]$ have shown both 
a relationship between $\mathrm{BP}$ and salt and a dose-response effect to salt reduction.

The Intersalt study [6] was performed in 52 centres throughout the world. Salt consumption, judged by 24-hour urinary sodium excretion, and blood pressure (BP) were measured following strict and uniform protocols. This study confirmed the link between salt intake and BP both within and between populations. Moreover, it was demonstrated that the increase in systolic (SBP) and diastolic (DBP) BP is agerelated and is steeper with higher sodium excretion. The EPIC cohort [7], which examined 23,100 community-living adults aged 45-79 years, identified differences in urinary sodium as markers of sodium intake associated with clinically relevant BP differences.

Because high BP favours cardiovascular disease (CVD) [10], a worldwide reduction of salt intake could substantially reduce the incidence of stroke, heart failure, and renal disease $[11,12 \bullet \cdot$. Despite a statistically significant heterogeneity among the studies, a meta-analysis of 13 prospective cohort studies on dietary salt intake and incidence of CVD [13] reported that a $2 \mathrm{~g}$ /day increase in sodium intake (5 $\mathrm{g}$ of salt) was associated with an overall increased risk of stroke (relative risk (RR) 1.23, $95 \%$ confidence interval (CI) 1.06$1.43, p=0.007$ ) and all CV events (RR 1.14, $95 \%$ CI 0.99 $1.32, p=0.07)$. Major sources of heterogeneity among studies were the geographic regions, differing substantially for dietary sodium intake, the estimation of sodium intake, which was based on a single 24-hour urinary collection, and the length of follow-up for the estimation of salt effect on CVD.

The causal effect of salt on CV risk is still debated, because observational studies of individuals on a free diet have reported an inverse relationship between $\mathrm{CV}$ events and salt intake [14••, 15-17]. A J-shaped curve relationship between salt and CVD was recently described [18••].

\section{Salt Sensitivity}

BP response to changes in salt intake varies considerably among individuals, independent of blood pressure levels [19]; this phenomenon is described as salt sensitivity of BP [20, 21]. Evidence support that this mechanism is partially under genetic control, because normotensive and hypertensive salt-sensitive individuals tend to have family history for hypertension more frequently than do those who are salt-resistant $[22,23]$. It also is known that salt sensitivity is more frequent in subjects of African origin and in older people [21].

Salt sensitivity is a negative prognostic indicator, because it is associated with increased incidence of cardiovascular complications [13], microalbuminuria [24], and endothelial dysfunction [25]. In previous studies, it has been assessed with different standardized protocols, including acute salt load, chronic dietary sodium interventions, and chronic sodium volume depletion.

The pathogenetic mechanisms of salt sensitivity are not clear; however, one hypothesis proposed is a larger renal reabsorption of sodium. The kidney has a central role in the relationship between sodium intake, total body sodium, fluid balance, and BP [26]. Guyton et al. [26] contributed to understand the role of kidneys by developing a complex computer model of the control mechanisms and feedback loops that regulate BP. A fundamental concept was pressure natriuresis, a mechanism through which the kidneys increase urinary output of fluids and salt to overcome excess of BP when it rises above normal. Cross-transplantation experiments in rats with inherited hypertension have strengthened the key role of the kidney in BP regulation by demonstrating that the kidney brings a "hypertensive" message. In fact, these studies have shown that the transplanted kidney from a young prehypertensive rat into a normotensive rat caused a chronic BP increase [27]. Indirect and more circumstantial evidence also are available in humans. A study on renal transplantation showed that recipients of a kidney from a donor with a negative family history for hypertension had lower BP than recipients from hypertensive families [28]. This concept has been consolidated in recent years by the identification of the molecular mechanisms that lead to increased sodium reabsorption in some forms of monogenic hypertension $[29,30]$.

Sodium contributes to more than $80 \%$ of the extracellular fluid osmolality and kidney participates in maintaining a constant extracellular environment that is necessary for a normal cell function. Sodium handling starts with filtration by the glomerulus and then it is reabsorbed along the tubule through an integrated system of carriers, channels, and pumps. The bulk of sodium reabsorption occurs in the proximal tubule and Henle's loop while the final qualitative changes are made in the collecting tubule. Sodium entry at this site occurs through selective sodium channels in the apical membrane, and the number of open channels is under hormonal control, being affected by aldosterone and atrial natriuretic peptide. Like most mammals, humans developed in a salt-poor environment. As a consequence, all the mechanisms that are related to sodium handling are focused on retaining sodium.

\section{Salt Sensitivity and Genes}

The studies published on the genetics of salt sensitivity have mainly followed a candidate gene approach. In humans, only one genome wide linkage scan, the Genetic Epidemiology Network of Salt Sensitivity (GenSalt) study [31], the largest family dietary sodium intervention, has addressed this issue. It was performed in Han Chinese rural population that underwent a high dietary salt intake. The dietary intervention included a 7-day low sodium intake (3 $\mathrm{g}$ 
of $\mathrm{NaCl}$ ) followed by a 7-day high sodium intake (17 $\mathrm{g}$ of $\mathrm{NaCl}$ ). Considerable heterogeneity exists among the different studies, mainly due to the definition and measurement of the phenotype and to ethnic differences. This heterogeneity results in conflicting findings and makes reliable comparisons difficult. Standardization in the measurement of the phenotype and replication in ethnically homogeneous populations is crucial to identify the true susceptibility genetic factors.

The genes associated with salt sensitivity phenotype have been recently reviewed by Felder et al. [32•], Kelly and He [33•], and Sanada et al. [34•]. In the present review, we report the most important findings.

\section{Renin-Angiotensin-Aldosterone System}

The genes of the renin-angiotensin-aldosterone system (RAAS) have been extensively studied because of their role in renal sodium handling. The aspartyl protease renin cleaves angiotensinogen (AGT) to angiotensin I, which is converted to angiotensin II (AGTII) by the angiotensinconverting (ACE) enzyme. AGTII binds to specific receptors on the cell membrane. AGTII produces vasoconstriction raising systemic BP. Moreover, AGTII both directly stimulates sodium transport in the proximal tubule and increases aldosterone release that leads to increased activity of the epithelial $\mathrm{Na}+(\mathrm{ENaC})$ channel. Through this mechanism, AGTII increases sodium and water reabsorption, expanding extracellular fluid volume, and increasing cardiac output and BP.

The INS/DEL polymorphism (I/D, rs4646994 or rs4340 or rs1799752 or rs13447447) is the most studied variant in the ACE gene, because it has been shown associated with serum ACE levels [35]. Most studies could not find any association with salt sensitivity [34•,36]. Although an association of the I allele with BP increase after a high salt intake has been reported, under either a recessive [37] or a dominant [38] model, whereas the $\mathrm{D}$ allele has been described associated to BP changes in another study [39].

Two studies $[40,41]$ reported a significant association between salt sensitivity and M235T polymorphism (rs699 T $>$ C) in the AGT gene. Patients with the TT genotype had the greatest increase in DBP, whereas no relationship was found with SBP [40]. Accordingly to this, the TT and the CT genotypes showed a significant reduction in SBP and DBP after low-sodium diet [41]. In AGT promoter a functional variant, in complete linkage disequilibrium with M235T, has been described (-6G>A, rs5051). The A allele is associated with increased gene transcription compatible with increased angiotensinogen level [42]. The AA genotype was found associated with greater BP decrease after sodium reduction [43].

The 11-beta-hydroxysteroids dehydrogenase (HSD11B2) gene has been studied since in the kidney the enzyme converts cortisol to the inactive cortisone. In this way, it prevents the improper activation by cortisol of the mineralcorticoid receptors that have similar affinities for cortisol and aldosterone. Mutations in HSD11B2 cause the syndrome of apparent mineralcorticoid excess and hypertension [44]. Three polymorphisms have been studied in relation to salt sensitivity: G534A (rs45483293) with one negative and one positive association, a CA-repeat in intron 1 and G-209A (rs45598932) that showed positive associations [34].

The GenSalt study identified several signals of association to low sodium intake in RAAS genes: rs4524238 and rs3772616 in angiotensin type 1 receptor (AGT1R), rs1557501 and rs2269372 in renin-binding protein (RENBP), and rs5479 in HSD11B2 [45]. These results refer to a Chinese population in which linkage disequilibrium structure can be different compared with a Western population and this could affect replication.

\section{Renal Ion Transporters}

Renal ion channels, transporters, and exchangers involved in regulation of sodium balance, blood volume, and BP have been extensively studied. The GenSalt study reported the first association between common variants in the $\mathrm{ENaC}$ genes and salt sensitivity. In the kidney, $\mathrm{ENaC}$ is localized in the distal nephron where the final tubular sodium reabsorption occurs. One exonic and five intronic SNPs of $\mathrm{ENaC} \gamma$-subunit were found associated with SBP response to low sodium [46]. Two of the five intronic SNPs have a possible enhancer activity on gene expression, but they need functional validation.

In the ascending limb of Henle's loop and in the distal convoluted tubule, transcellular sodium reabsorption is directly coupled to chloride reabsorption. Therefore, an alteration at this site could affect both sodium and chloride homeostasis. Two members of the chloride channels (CLC) gene family are predominantly expressed in the kidney: the CLCNKA in the thin ascending limb (TAL) of Henle's loop [47] and CLCNKB in the TAL, distal nephron, and macula densa [48]. The $1 \mathrm{p} 36$ locus harbours the two genes and emerged as a candidate when it was identified a strong activating mutation (Thr481Ser) in CLCNKB causing a sevenfold increase in $\mathrm{Cl}$ - transport when expressed in Xenopus oocytes [49]. The 481Ser allele was associated to higher BP in young normotensives [50]. Despite this association was not replicated [51-53], we described four new SNPs of CLCNKA associated with salt-sensitivity in never-treated hypertensives challenged with an acute sodium load [53].

$\mathrm{ENaC}$ is regulated by the serum/glucocorticoid regulated kinase 1 (SGK1) and by the Neural precursor cell Expressed Developmentally Down-regulated 4 Like (NEDD4L). SGK1 stimulates ENaC activity in the kidney by either increasing the residential time of the channels on the apical 
membrane or increasing $\mathrm{ENaC}$ gene transcription. NEDD4L affects the rate of sodium reabsorption in the distal nephron through an interaction with the PY motif and regulating $\mathrm{ENaC}$ cell surface expression by ubiquination. Rao et al. [54] recently demonstrated that carriers of the $T$ allele at rs2758151 and of G allele at rs9402571 in SGK1 have significantly higher SBP on high salt intake.

Carriers of the GG genotype at rs4149601 and of the CC genotype at rs2288774 in NEDD4L were more salt-sensitive and had lower plasma renin compared with noncarriers [55], suggesting a tendency to increased sodium reabsorption in carriers. Manunta et al. [56] described a combination of risk alleles in $\alpha$-adducin (ADD1) (rs4961), WNK1 (rs880054), and NEDD4L (rs4149601) that affects renal Na handling and BP response to thiazide treatment. WNK1 (WNK lysine deficient protein kinase 1) is a regulator of sodium transporters in the kidney.

Carey et al. [57] identified two common variants (rs7571842 and rs10177833) in the sodium-bicarbonate cotransporter gene (SLC4A5) that are strongly associated with salt sensitivity of blood pressure in two white independent populations. In renal tubular cells, SLC4A5 is involved in mantainance of costant intracellular $\mathrm{pH}$.

We recently identified SNPs in genes that regulate intracellular calcium and vascular tone associated with SBP. In hypertensives very accurately phenotyped for salt-sensitivity, we reported an association between SBP increase and SNPs in sodium/calcium exchanger member 1 (SLC9A1, rs434082 $\mathrm{G}>\mathrm{A}$ ) and sodium/potassium/calcium exchanger (SLC24A3, rs3790261 G>A) [58]. The involvement of SLC8A1 in the pathogenesis of salt sensitivity has been previously demonstrated [59]. In the same study [58], a cluster of SNPs in intron 1 of the type 1 cGMP-dependent protein kinase (PRKG1) gene was found associated with DBP increase in response to an acute salt load. PRKG1 is a nitrovasodilator effector that has been shown to mediate vascular smooth muscle cells relaxation.

\section{$\alpha$-Adducin}

The first paper describing the involvement of $\alpha$-adducin (ADD1) in salt sensitivity was published by our group [60] and showed that the $460 \mathrm{~W}$ allele of a functional polymorphism in ADD1 coding region (G460W, rs4961) was associated with a greater BP decrease after acute sodium load or long-term thiazide treatment. Adducin is a heterodimeric protein encoded by three closely related genes, $\alpha, \beta$, and $\gamma$, mapping on different chromosomes [61]. Adducin promotes and regulates the binding of spectrin with actin and directly binds actin and bundles actin filaments. It is present in many tissues and within regions of cell-cell contacts. Adducin can modulate the lattice structure of the cytoskeleton and the exposure of transmembrane proteins [62].
The G460W replacement, as described in silico analysis, causes a change from an aliphatic group to an aromatic group, which could be potentially damaging because it affects protein stability [63].

This variant increases the number and the activity of $\mathrm{Na}^{+}-$ $\mathrm{K}^{+}$-ATPase pump [64], the driving force of sodium transport reabsorption in renal epithelial cells. This probably explains why carriers of the $460 \mathrm{~W}$ allele, compared with wild-type carriers, are salt sensitive [60], have a less steep pressure natriuresis relationship [65], and present enhanced proximal reabsorption of sodium [66]. We also demonstrated a joint effect of the 460W allele and the DEL/DEL ACE genotype on $\mathrm{BP}$ response to an acute sodium load [67]. An independent study reported similar results in carriers of the $460 \mathrm{~W}$ allele on SBP changes from high- to a low-sodium intervention [68].

The GenSalt study examined seven SNPs in ADD1, including rs4961, as potential predictors of salt sensitivity [69], but reported no association for these variants. In this Chinese population a low-frequency variant, rs17833172, was significantly associated both with SBP and DBP response to high sodium and with DBP response to low sodium. Lack of association between rs4961 and salt sensitivity also was reported by two other studies [70, 71].

\section{Endothelial System}

The vascular endothelium plays a key role in BP regulation. The endothelial cells produce nitric oxide (NO), a very potent vasodilator synthesized from the aminoacid L-arginine by the endothelial nitric oxide synthase (eNOS) [72]. The endothelium expresses sodium channels, similar to those expressed in kidney tubular cells [73], regulated by the aldosterone [74] and whose activity is negatively correlated with NO release. Excess daily salt intake enhances vasoconstriction by decreasing production of NO via eNOS and increasing endothelial cell stiffness [75]. In humans, two studies reported an association between T-786C (rs2070744) polymorphism in the promoter of eNOS and BP response to salt intake [76, 77]. $\mathrm{NAD}(\mathrm{P}) \mathrm{H}$ dehydrogenase $[\mathrm{NAD}(\mathrm{P}) \mathrm{H}]$ is expected to reduce $\mathrm{NO}$ availability as $\mathrm{NO}$ also interact with superoxide ions generating peroxynitrite. Therefore, $\mathrm{NAD}(\mathrm{P}) \mathrm{H}$ oxidase gene could be a candidate gene in salt sensitivity and it appeared to be a susceptibility factor for salt sensitivity in women [78].

Despite a model of transgenic mice for endothelin-1 gene (ET-1), encoding a contracting factor produced by vascular endothelium, supported the involvement of this gene in salt-sensitivity [79], the GeneSalt study did not find any association between salt-sensitivity and variants in eNOS and ET-1.

The G1065A (rs5351) variant in the endothelin receptor subtype B (ETRB), encoding for a receptor mediating vasodilatation via nitric oxide, was described as significantly associated with salt sensitivity [80]. 


\section{Sympathetic Nervous and Dopaminergic Systems}

Increased sympathetic activity has been demonstrated in salt-sensitive hypertension and results in a) renal vasoconstriction with decreased renal blood flow and glomerular filtration rate, b) increased renal vascular resistance, c) increased renal tubular sodium and water reabsorption, and d) increased renal release of renin and norepinephrine [81-83].

In the sympathetic system, $\beta-2$ adrenergic receptors (ADRB2) may affect volume homeostasis through increased renin secretion [82]. Although not replicated by the GenSalt study, different reports identified an association between nonsynonymous coding variants in ADRB2 (G16R, rs1042713 and Q27E, rs1042714) and salt sensitivity [84-86].

The renal dopaminergic system, either by itself or via a synergistic interaction with other natriuretic factors, has a key role in renal natriuresis in presence of sodium excess [87]. An important player of the dopaminergic system in salt sensitivity is the G protein-coupled receptor kinase 4 (GRK4) [88•], which regulates type 1 dopamine receptors (D1R).

Functional polymorphisms (R65L rs2960306, A142V rs1024323, and A486V rs1801058) that increase basal GRK4 activity, decreasing D1R and increasing AGT1R activities, affect renal sodium excretion [89-92]. Animal studies also demonstrated that transgenic mice overexpressing GRK4A142V were hypertensive, whereas transgenic mice overexpressing the variant GRK4-A486V developed hypertension only when placed on a high-salt diet [87]. However, negative results also were reported in human studies [93].

\section{$\beta 3$ Subunit of G Protein}

G-proteins are transmembrane signal transducers that transmit signals from the cell surface to the intracellular environment. The GenSalt study reported that the minor allele at a new variant in guanine nucleotide-binding protein $\beta$-polypeptide 3 (GNB3), rs1129649, was associated with significantly decreased mean arterial pressure in response to low-sodium intervention [94].

\section{Conclusions}

Dietary sodium is an important contributor to hypertension, although blood pressure response to sodium, that is salt sensitivity, is very heterogeneous among individuals.

Despite few reports of an inverse relationship between cardiovascular events and salt intake, consensus exists on a causal relationship between chronic high-salt intake, high BP, and CVD. Controversy also exists about the beneficial effects that a reduction in population salt intake to the recommended level of $<5 \mathrm{~g} /$ day could have on health in all countries around the world.
Many studies have been conducted to elucidate the genetic determinants underlying BP response to salt intake. Considerable heterogeneity exists among these studies, mainly due to the definition and measurement of the phenotype and to ethnic differences, which makes comparison more difficult. This heterogeneity generated many conflicting results.

Much work is still necessary to delineate the genetic architecture of salt sensitivity. This could allow identifying specific genetic profiles of BP susceptibility to salt and to characterize individuals who could benefit from low-sodium dietary intervention to prevent hypertension.

\section{Compliance with Ethics Guidelines}

Conflict of Interest Sara Lupoli declares that she has no conflict of interest.

Erika Salvi declares that she has no conflict of interest.

Cristina Barlassina declares that she has no conflict of interest.

Human and Animal Rights and Informed Consent This article does not contain any studies with human or animal subjects performed by any of the authors.

\section{References}

Papers of particular interest, published recently, have been highlighted as:

- Of importance

-. Of major importance

1. World Health Organization: Diet, Nutrition and the prevention of chronic diseases: report of a joint $\mathrm{WHO} / \mathrm{FAO}$ expert consultation. Geneva, 28 January-1 February 2002 (WHO Technical Report Series; 916). Geneva; 2003.

2. James WP, Ralph A, Sanchez-Castillo CP. The dominance of salt in manufactured food in the sodium intake of affluent societies. Lancet. 1987;1:426-9.

3. Anderson CA, Appel LJ, Okuda N, et al. Dietary sources of sodium in China, Japan, the United Kingdom, and the United States, women and men aged 40 to 59 years: the INTERMAP study. J Am Diet Assoc. 2010;110:736-45.

4. Man CMD. Technological functions of salt in food products (chapter 8). In: Kilcast D, Angus F, editors. Reducing salt in foods: Practical strategies. Cambridge: CRC Press Woodhead Publishing Limited; 2007.

5. Ruskin A. Classics in arterial hypertension. Springfield: Charles CT; 1956. p. 164-272.

6. Intersalt: an international study of electrolyte excretion and blood pressure. Results of 24 hour urinary sodium and potassium excretion. Intersalt Cooperative Group. BMJ. 1988;297(6644):319-328.

7. Khaw KT, Bingham S, Welch A, et al. Blood pressure and urinary sodium in men and women: the Norfolk Cohort of the European Prospective Investigation into Cancer (EPIC-Norfolk). Am J Clin Nutr. 2004;80:1397-403.

8. Sacks FM, Svetkey LP, Vollmer WM, et al. DASH-Sodium Collaborative Research Group. Effects on blood pressure of reduced dietary sodium and the Dietary Approaches to Stop Hypertension (DASH) diet. N Engl J Med. 2001;344(1):3-10. 
9. He FJ, Mac Gregor GA. Effect of long term modest salt reduction on blood pressure. Cochrane Data-base Syst Rev. 2004;3, CD004937.

10. Lawes CM, Vander Hoorn S, Rodgers A. Global burden of bloodpressure-related disease, 2001. Lancet. 2008;371:1513-8.

11. World Health Organization: Reducing salt intake in populations: report of a WHO forum and technical meeting. WHO; 2007:1-60.

12. • He FJ, Burnier M, Macgregor GA. Nutrition in cardiovascular disease: salt in hypertension and heart failure. Eur Heart J. 2011;32(24):3073-80. A recent review on evidence for a causal relationship between salt intake, blood pressure (BP) and risk of cardiovascular disease (CVD).

13. Strazzullo P, D'Elia L, Kandala NB, Cappuccio F. Salt intake, stroke and cardiovascular disease: meta-analysis of prospective studies. BMJ. 2009;339:b4567.

14. •- Stolarz-Skrzypek K, Kuznetsova T, Thijs L, et al. Fatal and nonfatal outcomes, incidence of hypertension, and blood pressure changes in relation to urinary sodium excretion. JAMA. 2011;305(17):1777-85. A very recent population-based study that contradicts a large body of evidences that elevated sodium consumption is a risk factor for CVD and hypertension.

15. Alderman MH, Madhavan S, Cohen H, Sealey JE, Laragh JH. Low urinary sodium is associated with greater risk of myocardial infarction among treated hypertensive men. Hypertension. 1995;25(6):1145-52.

16. Cohen HW, Hailpern SM, Fang J, Alderman MH. Sodium intake and mortality in the NHANES II follow up study. Am J Med. 2006;119(3):275.e7-14.

17. Cohen HW, Hailpern SM, Alderman MH. Sodium intake and mortality follow up in the Third National Health and Nutrition Examination Survey (NHANES III). J Gen Intern Med. 2008;23(9):1297-302.

18. •- O'Donnell MJ, Yusuf S, Mente A, Gao P. Urinary sodium and potassium excretion and risk of cardiovascular events. JAMA. 2011;306(20):2229-38. A paper supporting the view that sodium intake bears a "J-shaped" relation to CVD outcomes.

19. Campese VM. Salt sensitivity in hypertension: renal and cardiovascular implications. Hypertension. 1994;23:531-50.

20. Weiberger MH. Salt sensitivity of blood pressure in humans. Hypertension. 1996;27(3):481-9.

21. Luft FC, Weiberger MH. Heterogeneous responses to changes in dietary salt intake: the salt-sensitivity paradigm. Am J Clin Nutr. 1997;65:612S-7.

22. Luft FC, Miller JZ, Weinberger MH, Christian JC, Skrabal F. Genetic influences on the response to dietary salt reduction, acute salt loading or salt depletion in humans. J Cardiovasc Pharmacol. 1988;12 Suppl 3:S49-55.

23. Sharma AM. Salt sensitivity as a phenotype for genetic studies of human hypertension. Nephrol Dial Transplant. 1996;11:927-9.

24. Bihorac A, Tezcan H, Ozener C, Oktay A, Akoglu E. Association between salt sensitivity and target organ damage in essential hypertension. Am J Hypertens. 2000;13(8):864-72.

25. Bragulat E, de la Sierra A, Antonio MT, Coca A. Endothelial dysfunction in salt-sensitive hypertension. Hypertension. 2001;37:444 8.

26. Guyton AC, Coleman TG, Cowley AW, et al. Arterial pressure regulation: overriding dominance of the kidneys in long-term regulation and in hypertension. Am J Med. 1972;52:584-94.

27. Rettig R, Bandelow N, Patschan O, et al. The importance of the kidney in primary hypertension: insights from cross-transplantation. $\mathrm{J}$ Hum Hypertens. 1996;10:641-4.

28. Guidi E, Bianchi G, Rivolta E, et al. Hypertension in man with a kidney transplant: role of familial versus other factors. Nephron. 1985;41:14-21.

29. Hansson JH, Schild L, Lu Y, et al. A de novo missense mutation of the beta subunit of the epithelial sodium channel causes hypertension and Liddle syndrome, identifying a proline-rich segment critical for regulation of channel activity. Proc Natl Acad Sci U S A. 1995;92(25):11495-9.

30. Mune T, Rogerson FM, Nikkilä H, Agarwal AK, White PC. Human hypertension caused by mutations in the kidney isozyme of 11 beta-hydroxysteroid dehydrogenase. Nat Genet. 1995;10(4): 394-9.

31. GenSalt Collaborative Research G. GenSalt: rationale, design, methods and baseline characteristics of study participants. J Hum Hypertens. 2007;21:639-46.

32. • Felder RA, White MJ, Williams SM, Jose PA. Diagnostic tools for hypertension and salt sensitivity testing. Curr Opin Nephrol Hypertens. 2013;22:65-76. An updated review of salt sensitivity and genetics.

33. - Kelly TN, He J. Genomic epidemiology of blood pressure salt sensitivity. J Hypertens. 2012;30:861-73. An updated review on genetics of salt sensitivity.

34. - Sanada H, Jones JE, Jose PA. Genetics of salt-sensitive hypertension. Curr Hypertens Rep. 2011;13:55-66. An updated review of salt sensitivity and genetics.

35. Rigat B, Hubert C, Alhenc-Gelas F, Cambien F. An insertion/ deletion polymorphism in the angiotensin I-converting enzyme gene accounting for half the variance of serum enzyme levels. J Clin Invest. 1990;86(4):1343-6.

36. Beeks E, Kessels AGH, Kroon AA, van der Klauw MM, de Leeuw PW. Genetic predisposition to salt-sensitivity: a systematic review. J Hypertens. 2004;22:1243-9.

37. Hiraga H, Oshima T, Watanabe M, et al. Angiotensin I-converting enzyme gene polymorphism and salt sensitivity in essential hypertension. Hypertension. 1996;27:569-72.

38. Poch E, Gonzalez D, Giner V, et al. Molecular basis of salt sensitivity in human hypertension. Evaluation of renin-angiotensin aldosterone system gene polymorphisms. Hypertension. 2001;38:1204-9.

39. Dengel DR, Brown MD, Ferrell RE, Supiano MA. Role of angiotensin converting enzyme genotype in sodium sensitivity in older hypertensives. Am J Hypertens. 2001;14:1178-84.

40. Johnson AG, Nguyen TV, Davis D. Blood pressure is linked to salt intake and modulated by the angiotensinogen gene in normotensive and hypertensive elderly subjects. J Hypertens. 2001;19:1053-60.

41. Hunt SC, Geleijnse JM, Wu LL, et al. Enhanced blood pressure response to mild sodium reduction in subjects with the 235T variant of the angiotensinogen gene. Am J Hypertens. 1999;12: $460-6$.

42. Jeunemaitre X, Inoue I, Williams C, Charru A. Haplotypes of angiotensinogen in essential hypertension. Am J Hum Genet. 1997;60:1448-60.

43. Hunt SC, Cook NR, Oberman A, et al. Angiotensinogen genotype, sodium reduction, weight loss, and prevention of hypertension: trials of hypertension prevention, phase II. Hypertension. 1998;32:393401.

44. White PC, Agarwal AK, Nunez BS, et al. Genotype-phenotype correlations of mutations and polymorphisms in HSD11B2, the gene encoding the kidney isozyme of 11 beta-hydroxysteroid dehydrogenase. Endocr Res. 2000;26(4):771-80.

45. Gu D, Kelly TN, Hixson JE, et al. Genetic variants in the reninangiotensin-aldosterone system and salt sensitivity of blood pressure. J Hypertens. 2010;28:1210-20.

46. Zhao Q, Gu D, Hixson JE, et al. Common variants in epithelial sodium channel genes contribute to salt-sensitivity of blood pressure: the GenSalt Study. Circ Cardiovasc Genet. 2011;4:375-80.

47. Uchida S, Sasaki S, Nitta K, et al. Localization and functional characterization of rat kidney-specific chloride channel. CLC-K1. J Clin Invest. 1995;96:104-13.

48. Yoshikawa M, Uchida S, Yamauchi A, Miyai A. Localization of rat CLC-K2 chloride channel mRNA in the kidney. Am J Physiol Renal Physiol. 1999;276:F552-8. 
49. Jeck N, Waldegger P, Doroszewicz J, et al. A commom sequence variation of the CLCNKB gene strongly activates $\mathrm{ClC}-\mathrm{Kb}$ chloride channel activity. Kidney Int. 2004;65:190-7.

50. Jeck N, Waldegger S, Lampert A, Boehmer C. Activating mutation of the renal epithelial chloride channel $\mathrm{ClC}-\mathrm{Kb}$ predisposing to hypertension. Hypertension. 2004;43:1175-81.

51. Speirs HJ, Wang WY, Bejafield AV, Morris BJ. No association with hypertension of CLCNKB and TNFRSF1B polymorphisms at a hypertension locus on chromosome 1p36. J Hypertens. 2005;23: 1491-6.

52. Kokubo Y, Tomoike H, Tanaka C, et al. Association analysis between hypertension and CYBA, CLCNKB and KCNMB1 functionl polymorphisms in the Japanese population; the Suita study. Circ J. 2005;69:138-42.

53. Barlassina C, Dal Fiume C, Lanzani C, et al. Common genetic variants and haplotypes in renal CLCNKA gene are associated to salt-sensitive hypertension. Hum Mol Genet. 2007;16(13):1630-8.

54. Rao AD, Sun B, Saxena A, et al. Polymorphisms in the serum- and glucocorticoid-inducible kinase 1 gene are associated with blood pressure and renin response to dietary salt intake. J Hum Hypertens. 2013;27:176-80.

55. Dahlberg J, Nilsson LO, von Wowern F, Melander O. Polymorphism in NEDD4L is associated with increased salt sensitivity, reduced levels of P-renin and increased levels of Nt-proANP. PLoS One. 2007;2(5):e432.

56. Manunta $\mathrm{P}$, Lavery $\mathrm{G}$, Lanzani $\mathrm{C}$, et al. Physiological interaction between alpha-adducin and WNK1-NEDD4L pathways on sodium-related blood pressure regulation. Hypertension. 2008;52(2):366-72.

57. Carey RM, Schoeffel CD, Gildea JJ, et al. Salt sensitivity of blood pressure is associated with polymorphisms in the sodiumbicarbonate cotransporter. Hypertension. 2012;60:1359-66.

58. Citterio L, Simonini M, Zagato L, et al. Genes involved in vasoconstriction and vasodilation system affect salt-sensitive hypertension. PLoS One. 2011;6(5):e19620.

59. Blaustein MP, Zhang J, Chen L, et al. The pump, the exchanger, and endogenous ouabain: signaling mechanisms that link salt retention to hypertension. Hypertension. 2009;53:291-8.

60. Cusi D, Barlassina C, Azzani T, et al. Polymorphisms of alphaadducin and salt sensitivity in patients with essential hypertension. Lancet. 1997;349(9062):1353-7.

61. Joshi R, Gilligan DM, Otto R, McLaughlin T, Bennett V. Primary structure and domain organization of human alpha and beta adducing. J Cell Biol. 1991;115:665-75.

62. Matsuoka Y, Li X, Bennett V. Adducin: structure, function and regulation. Cell Mol Life Sci. 2000;57:884-95.

63. Kundu A, Anand A. Computational study of ADD1 gene polymorphism associated with hypertension. Cell Biochem Biophys. 2013;65(1):13-9.

64. Efendiev R, Krmar RT, Ogimoto G, et al. Hypertension-linked mutation in the adducin alpha-subunit leads to higher AP2-mu2 phosphorylation and impaired $\mathrm{Na}+, \mathrm{K}+$-ATPase trafficking in response to GPCR signals and intracellular sodium. Circ Res. 2004;95(11):1100-8.

65. Manunta P, Cusi D, Barlassina C, et al. Alpha-adducin polymorphisms and renal sodium handling in essential hypertensive patients. Kidney Int. 1998;53(6):1471-8.

66. Manunta P, Burnier M, D'Amico M, Buzzi L, et al. Adducin polymorphism affects renal proximal tubule reabsorption in hypertension. Hypertension. 1999;33(2):694-7.

67. Barlassina C, Schork NJ, Manunta P, et al. Synergistic effect of aadducin and ACE genes causes blood pressure changes with body sodium and volume expansion. Kidney Int. 2000;57(3):1083-90.

68. Grant FD, Romero JR, Jeunemaitre X, Hunt SC. Low-renin hypertension, altered sodium homeostasis, and an alpha-adducin polymorphism. Hypertension. 2002;39(2):191-6.
69. Kelly TN, Rice TK, Gu D, et al. Novel genetic variants in the alpha-adducin and guanine nucleotide binding protein betapolypeptide 3 genes and salt sensitivity of blood pressure. Am J Hypertens. 2009;22(9):985-92.

70. Castejon AM, Alfieri AB, Hoffmann IS. Alpha-adducin polymorphism, salt sensitivity, nitric oxide excretion, and cardiovascular risk factors in normotensive Hispanics. Am J Hypertens. 2003; 16(12):1018-24.

71. Ciechanowicz A, Widecka K, Drozd R, et al. Lack of association between Gly460Trp polymorphism of alpha-adducin gene and salt sensitivity of blood pressure in Polish hypertensives. Kidney Blood Press Res. 2001;24(3):201-6.

72. Palmer RMJ, Ashton DS, Moncada S. Vascular endothelial cells synthesize nitric oxide from L-arginine. Nature. 1988;333:664-6.

73. Vigne P, Champigny G, Marsault R, et al. A new type of amiloridesensitive cationic channel in endothelial cells of brain microvessels. J Biol Chem. 1989;264(13):7663-8.

74. Golestaneh N, Klein C, Valamanesh F, et al. Mineralocorticoid receptor-mediated signaling regulates the ion gated sodium channel in vascular endothelial cells and requires an intact cytoskeleton. Biochem Biophys Res Commun. 2001;280(5):1300-6.

75. Toda N, Arakawa K. Salt-induced hemodynamic regulation mediated by nitric Oxide. J Hypertens. 2011;29(3):415-24.

76. Miyaki K, Tohyama S, Murata M, et al. Salt intake affects the relation between hypertension and the T-786C polymorphism in the endothelial nitric oxide synthase gene. Am J Hypertens. 2005;18(12 Pt 1):1556-62.

77. Dengel DR, Brown MD, Ferrell RE, Reynolds TH, Supiano MA. A preliminary study on T-786C endothelial nitric oxide synthase gene and renal hemodynamic and blood pressure responses to dietary sodium. Physiol Res. 2007;56(4):393-401.

78. Castejon AM, Bracero J, Hoffmann IS, Alfieri AB, Cubeddu LX. $\mathrm{NAD}(\mathrm{P}) \mathrm{H}$ oxidase p22phox gene $\mathrm{C} 242 \mathrm{~T}$ polymorphism, nitric oxide production, salt sensitivity and cardiovascular risk factors in Hispanics. J Hum Hypertens. 2006;20(10):772-9.

79. Shindo T, Kurihara H, Maemura K, et al. Renal damage and saltdependent hypertension in aged transgenic mice overexpressing endothelin-1. J Mol Med(Berl). 2002;80(2):105-16.

80. Caprioli J, Mele C, Mossali C, et al. Polymorphisms of EDNRB, ATG, and ACE genes in salt-sensitive hypertension. Can J Physiol Pharmacol. 2008;86(8):505-10.

81. Stella A, Zanchetti A. Interactions between the sympathetic nervous system and the kidney: experimental observations. J Hypertens Suppl. 1985;3(4):S19-25.

82. DiBona GF. Sympathetic nervous system and the kidney in hypertension. Curr Opin Nephrol Hypertens. 2002;11(2):197200.

83. Yatabe MS, Yatabe J, Yoneda M, et al. Salt sensitivity is associated with insulin resistance, sympathetic overactivity, and decreased suppression of circulating renin activity in lean patients with essential hypertension. Am J Clin Nutr. 2010;92(1):77-82.

84. Svetkey LP, Harris EL, Martin E, et al. Modulation of the BP response to diet by genes in the renin-angiotensin system and the adrenergic nervous system. Am J Hypertens. 2011;24(2):209-17.

85. Sun B, Williams JS, Svetkey LP, Kolatkar NS, Conlin PR. Beta2adrenergic receptor genotype affects the renin-angiotensin-aldosterone system response to the Dietary Approaches to Stop Hypertension (DASH) dietary pattern. Am J Clin Nutr. 2010;92(2):444-9.

86. Pojoga L, Kolatkar NS, Williams JS, et al. Beta-2 adrenergic receptor diplotype defines a subset of salt-sensitive hypertension. Hypertension. 2006;48(5):892-900.

87. Jose PA, Soares-da-Silva P, Eisner GM, Felder RA. Dopamine and $\mathrm{G}$ protein-coupled receptor kinase 4 in the kidney: role in blood pressure regulation. Biochim Biophys Acta. 2010;398:553-8.

88. - Harris RC. Abnormalities in renal dopamine signaling and hypertension: the role of GRK4. Curr Opin Nephrol Hypertens. 
2012;21:61-5. An updated review of the role of dopamine, dopamine receptors, and GRK4 in the regulation of blood pressure.

89. Felder RA, Sanada H, Xu J, et al. G protein-coupled receptor kinase 4 gene variants in human essential hypertension. Proc Natl Acad Sci USA. 2002;99:3872-7.

90. Lohmueller KE, Wong LJ, Mauney MM, et al. Patterns of genetic variation in the hypertension candidate gene GRK4: ethnic variation and haplotype structure. Ann Hum Genet. 2006;70:27-41.

91. Sanada H, Yatabe J, Midorikawa S, et al. Single-nucleotide polymorphisms for diagnosis of salt-sensitive hypertension. Clin Chem. 2006;52:352-60.
92. Bengra C, Mifflin TE, Khripin Y, et al. Genotyping essential hypertension SNPs using a homogenous PCR method with universal energy transfer primers. Clin Chem. 2002;48:213140.

93. Staessen JA, Kuznetsova T, Zhang H, et al. Blood pressure and renal sodium handling in relation to genetic variation in the DRD1 promoter and GRK4. Hypertension. 2008;51:1643-50.

94. Kelly TN, Rice TK, Gu D, et al. Novel genetic variants in the alpha-adducin and guanine nucleotide binding protein betapolypeptide 3 genes and salt sensitivity of blood pressure. Am J Hypertens. 2009;22:985-92. 